\title{
MARINE DIESEL ENGINES OPERATING CYCLE SIMULATION FOR DIAGNOSTICS ISSUES
}

\author{
Dmytro S. MincheV ${ }^{a, *}$, Roman A. VARBAnets ${ }^{b}$, \\ Nadiya I. Alexandrovskaya ${ }^{b}$, Ludmila V. Pisintsaly ${ }^{b}$ \\ ${ }^{a}$ National University of Shipbuilding, Internal Combustion Engines, Plants and Technical Maintenance \\ Department, Heroyiv Ukrayiny ave., 9, 54025 Mykolaiv, Ukraine \\ ${ }^{b}$ Odessa National Maritime University, Marine Engineering Department, 34 Mechnikov Str., 65029 Odessa, \\ Ukraine \\ * corresponding author: misaidima@gmail.com
}

\begin{abstract}
The ongoing monitoring of marine diesel engines helps to detect the deviations of its parameters early and prevent major failures. But the experimental diagnostics data are generally limited, so frequently, it isn't possible to get all the necessary information to make a clear decision. The mathematical simulation could be used to clarify the experimental data and to provide a deeper understanding of engine conditions. In this paper, the MAN 6L80MCE marine diesel engine of "Father S" bulk carrier diagnostics issues are considered. The diagnostics data were collected with DEPAS Handy equipment and present the information about indicated processes by every engine cylinder. The on-line resource Blitz-PRO was used for the simulation of the engine operation and helped to prove that the variation in exhaust valve's closing timing is responsible for the observed compression pressure difference, while the irregularity in fuel injection causes the considerable difference in the maximum pressure.
\end{abstract}

KEYworDS: Mathematical simulation, valve train, fuel injection, mathematical-based diagnostics.

\section{INTRODUCTION}

The marine diesel engines diagnostics aims to determine actual conditions of the engine in terms of fuel efficiency, reliability and correct the operation of its subsystems, such as the fuel injection system, supercharging system, valve train, etc. However, in the case of quick diagnostics, especially during normal vessel operation, there are only limited possibilities for correct measurements of all engine parameters. Mathematical simulation of engine's operating cycle could be used for these cases to clarify the possible issues and to refer particular engine operation conditions to a benchmark. Mathematical-based fault diagnostics are becoming a very promising approach. The idea is to define the difference between the actual value and the modelled value of a signal being measured [1] 3 . Different types of mathematical models are used, depending on the diagnostic tasks 4 , 5. Neural networks based models, which can generate a decision during the engine operation, could also be applied [6. DEPAS Handy is the set of diagnostics tools developed for main and auxiliary marine diesel engines. It allows measuring the in-cylinder pressure diagram together with vibrodiagrams of fuel injection, intake and exhaust valves closing [7] 9 ]. In practice, due to complex interrelations of gas-exchange, fuel-injection, supercharging processes, environmental parameters, warm-up conditions of an engine, etc. it is rather difficult to precisely define the real issue during an engine diagnostic procedure. A mathematical simulation may help to make the final decision. Blitz-PRO is the online internal combustion engine's operating cycle simulation tool 10. It provides static and transient compression-ignition, spark-ignition and dual-fuel engines' operating cycle simulation from any device, which has access to internet and does not require installation. Blitz-PRO can be used to accumulate statistics for the given engine during its operation time, which could be useful for analyses of the current engine conditions. In this paper, Blitz-PRO is used to analyse and clarify the diagnostics data from DEPAS Handy for the MAN 6L80MCE main marine diesel engine.

\section{MATHEMATICAL MODEL DEVELOPMENT}

Blitz-PRO offers operating cycle synthesis for various configurations of ICE engines. Nevertheless, for any engine configuration, the basic approach remains the same: the engine is divided into couple of open thermodynamic systems (OTS), which interact with each other by energy and mass exchange processes. Three types of OTS are applied depending on computational tasks:

(1.) single-zone 0-dimensional (0-D) quasi-steady model;

(2.) two-zone 0-D quasi-steady model; 
(3.) 1-D unsteady model.

For 0-D OTS, the universal set of equations is used. These equations are based on the concepts of the first-law of thermodynamics, equality of working gases' properties for each point of the volume, gas-state law and mass balance equations.

The first law of thermodynamics is expressed as:

$$
\begin{aligned}
& \frac{d I_{\text {fuel }}}{d \varphi}+\sum_{j=1}^{n_{1}} \frac{d I_{j}}{d \varphi}+\frac{\delta Q_{\text {comb }}}{d \varphi}+\sum_{i=1}^{n_{2}} \frac{\delta Q_{\text {wall. } i}}{d \varphi}= \\
& c_{v m} T\left(\sum_{j=1}^{n_{1}} \frac{d m_{j}}{d \varphi}+\frac{d m_{f u e l}}{d \varphi}\right)+c_{v} m \frac{d T}{d \varphi}+m T \frac{d\left(c_{v m}\right)_{T}}{d \varphi}+p \frac{d V}{d \varphi},
\end{aligned}
$$

where $d I_{f u e l} / d \varphi, d I_{j} / d \varphi$ - the rates of enthalpy change due to fuel evaporation and due to mass exchange processes, respectively, $\delta Q_{\text {comb }} / d \varphi$ - the heat release rate due to fuel combustion, $\delta Q_{w a l l . i} / d \varphi-$ the heat transfer rate to the walls of the system, $d m_{f u e l} / d \varphi, d m_{j} / d \varphi$ - the fuel mass flow and gases mass flow, respectively, $n_{1}-$ the number of the interacting thermodynamic systems, involved in the mass exchange process, $n_{2}-$ the number of walls, involved in the heat transfer process, $p, T, V, m$-the pressure, temperature, volume, mass of the gases mixture in the OTS, respectively, $c_{v}, c_{v m}$ - the actual and average isochoric specific heat capacity, respectively.

The equation of thermodynamics first law is completed with the mass balance equation and with the gas-state equation:

$$
\begin{aligned}
& d m=\sum_{j=1}^{n_{1}} d m_{j}+d m_{f u e l} \\
& p V=Z \frac{m}{\mu} R T
\end{aligned}
$$

where $\mathrm{Z}$ is the compression factor, calculated by the Berthelot equation:

$$
Z=1+\frac{9}{128} \frac{\pi}{\theta}\left(1+\frac{6}{\theta^{2}}\right)
$$

where $\pi=p / p_{\text {crit }}$ - relative to the critical pressure, $\theta=T / T_{\text {crit }}$ - relative to the critical temperature.

Generally, for each open thermodynamic system, the single-zone model is applied, this means that the whole volume of the system is considered as a homogeneous mixture of gases. However, for several cases, the two-zone model is also implemented:

(1.) During the combustion period to predict the burned gases and fresh charge temperatures for NOx and CO formation calculation.

(2.) During the scavenging period, for two-stroke engines, to correctly predict gas exchange processes.

(3.) To consider burned gases reflux from the cylinder into the intake receiver.

In the two-zone model, the thermodynamic system is virtually divided into two interacting thermodynamic systems. The general concept for the two-zone model is the equivalence of pressure for both zones and impenetrable flexible boundary surface between them. Basic equations are the application of the first law of thermodynamics:

$$
\left\{\begin{array}{l}
\frac{d I_{\text {fuel }}}{d \varphi}+\sum_{j=1}^{n_{1}} \frac{d I_{j}^{I}}{d \varphi}+\frac{d I_{I-I I}}{d \varphi}+\frac{\delta Q_{\text {comb }}}{d \varphi}+\sum_{i=1}^{n_{2}} \frac{\delta Q_{\text {wall.i }}^{I}}{d \varphi}+\frac{\delta Q_{I-I I}}{d \varphi}=\frac{d I^{I}}{d \varphi}+V^{I} \frac{d p}{d \varphi} \\
\sum_{j=1}^{n_{3}} \frac{d I_{j}^{I I}}{d \varphi}-\frac{d I_{I-I I}}{d \varphi}+\sum_{i=1}^{n_{2}} \frac{\delta Q_{\text {wall.i }}^{I I}}{d \varphi}-\frac{\delta Q_{I-I I}}{d \varphi}=\frac{d I^{I I}}{d \varphi}+V^{I I} \frac{d p}{d \varphi}
\end{array}\right.
$$

where index "I" refers to the burned gases zone, and index "II" to the fresh mixture zone, $\delta Q_{I-I I} / d \varphi$ is the heat transfer rate between zones, $\delta I_{I-I I} / d \varphi$ is the enthalpy transfer rate between the zones, $d I^{I} / d \varphi, d I^{I I} / d \varphi$ are the corresponding enthalpy change rates for zone I and II.

These equations are used together with a general single-zone equation, which is used to find the pressure for the next time layer. 
The mass flow between the interacting 0-D thermodynamic systems is calculated with a quasi-steady adiabatic nozzle concept coupled with prof. Orlin's approach to consider unsteady effects. The quasi-steady equations for gas flow velocity $w_{\text {static }}$ from the volume with the higher pressure " 1 " to the volume with the lower pressure " 2 " are:

$$
w_{\text {static }}=\left\{\begin{array}{l}
\sqrt{\frac{2 k_{1}}{k_{1}+1} R_{\mu} T_{1}^{*}}, \quad \text { if } \frac{p_{1}}{p_{2}} \geq\left(\frac{2}{k_{1}+1}\right)^{\frac{k_{1}}{1-k_{1}}} \\
\sqrt{\frac{2 k_{1}}{k_{1}-1} R_{\mu} T_{1}^{*}\left[1-\left(\frac{p_{2}}{p_{1}^{*}}\right)\right]^{\frac{k_{1}-1}{k_{1}}}}, \quad \text { otherwise, }
\end{array}\right.
$$

where $k_{1}$ is the adiabatic exponent, "*" indicates total parameters.

To consider the unsteady phenomena, the pulse conservation equation is used:

$$
w \frac{\partial w}{\partial x}+\frac{\partial w}{\partial t}=-\frac{1}{\rho} \frac{\partial p}{\partial x}
$$

It is converted to expresses the gas flow acceleration:

$$
\frac{d w}{d \tau}=\frac{w_{\text {static }}\left|w_{\text {static }}\right|-w|w|}{2 L}
$$

where $L$ is the "active" pipe length. The active pipe length is to be set by the user for the intake and exhaust valves/ports, but for many other cases (turbine, compressor, intercooler, etc.) it is assumed automatically (usually divisible by channel's equivalent flow diameter).

The 1-D unsteady models are used to consider unsteady effects of gas flow in the intake and exhaust systems. The following set of equations is applied:

$$
\left\{\begin{array}{l}
\frac{\partial \rho}{\partial \tau}+w \frac{\partial \rho}{\partial x}+\rho \frac{\partial w}{\partial x}=-\lambda_{\text {fric }} \frac{w|w|}{2 d} \\
\frac{\partial w}{\partial \tau}+w \frac{\partial w}{\partial x}+\frac{1}{\rho} \frac{\partial p}{\partial x}=-w \rho \frac{d \ln f}{d x} \\
\frac{\partial S}{\partial \tau}+w \frac{\partial S}{\partial x}=\frac{1}{T}\left(\lambda_{\text {fric }} \frac{\left|w^{3}\right|}{2 d}-\frac{4 \alpha}{\rho d}\left(T_{\text {wall }}-T\right)\right) \\
S-S_{n o}=\frac{R_{\mu}}{k-1} \frac{p / p_{n o}}{\left(\rho / \rho_{n o}\right)^{k}}
\end{array}\right.
$$

where $\lambda_{\text {fric }}$ - the coefficient of friction, $\alpha$ - the heat transfer coefficient from gas to the pipe wall, $T_{w a l l}-$ the pipe wall temperature, $T$ - the gas temperature, $S$ - entropy, "no" - refers to normal conditions, $d$ - the pipe diameter, $k$ - the adiabatic exponent.

The size $h$ of the computational cells for 1-D model is calculated according to the CFL condition:

$$
h=\frac{L_{\text {pipe }}}{\left(a+\left|w_{\max }\right|\right) \frac{\Delta \varphi_{\max }}{6 n_{\text {crank }}}},
$$

where $L_{\text {pipe }}$ - the length of the runner, $a$ - the local sonic speed, $w_{\max }$ - maximum gas velocity, $\Delta \varphi_{\max }-$ the maximum calculation time step by the crank angle degree (as the variable time-step mesh generation available in Blitz-PRO [11]), $n_{\text {crank }}$ - crankshaft speed.

The heat transfer processes and wall temperatures are considered using a quasi-steady approach. The Woschni equation [12] is used to find the heat transfer coefficient from gases to cylinder walls:

$$
\alpha_{g a s}=A \frac{(10 p)^{0.8}}{T^{0.53} D_{c y l}^{0.2}}\left[C_{1} c_{m}+C_{2} \frac{\left(p-p_{m o t}\right) V_{d} T}{1000 p V}\right]^{0.8}
$$

where $A, C_{1}, C_{2}$ - coefficients, $p_{m o t}$ - pressure in the cylinder during running motor condition. 


\begin{tabular}{llllll}
\hline $\begin{array}{l}\text { Cyl. } \\
\text { nmbr }\end{array}$ & rpm & $\begin{array}{l}p_{\max } \\
\text { bar }\end{array}$ & $\begin{array}{l}p_{\text {compr }} \\
\text { bar }\end{array}$ & $\begin{array}{l}\alpha_{\text {ing }} \\
\text { c.a.d. }\end{array}$ & $\begin{array}{l}\varphi_{\text {inj }} \\
\text { c.a.d. }\end{array}$ \\
\hline 1 & 66 & 75.1 & 61.3 & -2.7 & 12 \\
2 & 66 & 68.5 & 57.1 & -3.2 & 9.6 \\
3 & 66 & 72.6 & 55.5 & -2.6 & 9.2 \\
4 & 66 & 66.6 & 55.9 & -4.9 & 10.4 \\
5 & 66 & 66.4 & 52.3 & -3.9 & 9.6 \\
6 & 66 & 64.7 & 54.8 & -4.2 & 9.5 \\
1 & 75 & 89 & 74.2 & -1.3 & 14.1 \\
2 & 75 & 80.3 & 69.6 & -3.1 & 12 \\
3 & 75 & 84.5 & 67.4 & -3 & 12.6 \\
4 & 75 & 79.2 & 68.5 & -4.9 & 12.5 \\
5 & 75 & 76.2 & 64.6 & -4.5 & 13.3 \\
6 & 75 & 75.2 & 65.9 & -4.4 & 11.2 \\
\hline
\end{tabular}

TABLE 1. Results of MAN 6L80MCE engine diagnostics with DEPAS Handy.

The Razleitzev fuel injection-evaporation-combustion model is applied to define the heat release rate [13:

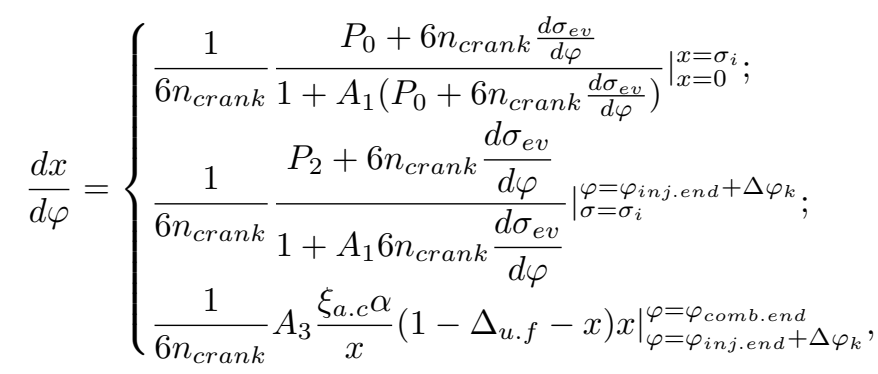

where $x$ - burned fuel fraction, $\sigma_{i}$ represents the amount of fuel injected during the ignition delay, $\sigma_{e v}$ - evaporated fuel fraction, $\varphi_{\text {inj.end }}$ - the moment of the injection end, $\Delta \varphi_{k}$ - extension of the second equation usage time, $\xi_{a . c}$ - function of air usage, $\Delta_{u . f}$ - unburned fuel fraction, $P_{0}, P_{2}, A_{0}, A_{2}$ - functions.

The Runge-Kutta second order implicit method is applied to numerically solve the sets of equations for interacting OTS. The working medium density relative accuracy for all open thermodynamic systems is used as the condition of the correct solution. The adaptive fixed-point numerical method is used to avoid looping the calculations.

\section{Mathematical Simulation FOR DiAgnostics ISSUES}

The MAN 6L80MCE main diesel engine is installed on the "Father S" bulk carrier. It is equipped with two ABB VTR564 turbochargers and directly drives the fixed pitch propeller. The measurements made with the DEPAS Handy equipment include two sets of indicated diagrams and vibrodiagrams of the fuel injection and exhaust valves closing for the engine running at 66 and $75 \mathrm{rpm}$. The diagrams in Figure 1 and Table 1 show a huge difference in the compression and maximum pressure between the cylinders. The injection advance is late by about $\alpha_{i n j}=-2 \ldots-5$ c.a.d. before the TDC and considerably uneven as well as the injection duration $\varphi_{i n j}$. As a conclusion of measurements, the engine operates normally, but the true reason of the huge difference in the maximum and compression pressures between the cylinders as well as its influence on engine overall efficiency needs to be discovered.

We used mathematical simulations of MAN 6L80MCE diesel operating cycle to clarify the experimental results. To set-up and calibrate the Blitz-PRO mathematical model, we used official sea trials results of the "Father S" bulk carrier combined with the manufacturer's manuals information. The main task of the initial set-up of the mathematical model was to get the engine operation parameters, which are referred as its normal conditions. The important issues for this case of mathematical model set-up were the turbocharger's performance maps and the actual exhaust valve diagram.

Turbocharger performance maps, used for the ABB VTR564 turbocharger emulation are based on the information from [15] (see Figure 2). These maps are extrapolated and interpolated according to [16, 17] and presented in Figure 33. A further identification of the turbocharger performance was made by a comparison of the sea trail, DEPAS Handy experimental data and the Blitz-PRO simulation results.

The relative exhaust valve lift diagram, used for the simulation, is shown in Figure 5 b and is based on the MAN market update note [14. It is clear that the exhaust lobe profile aims to decrease the speed of the valve 


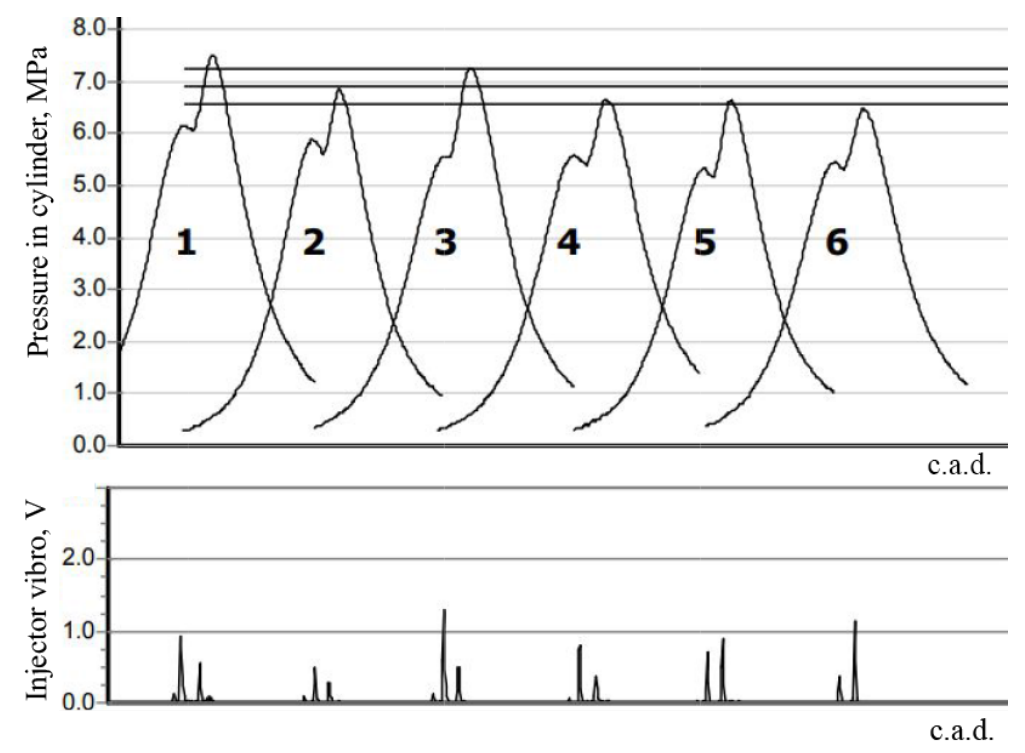

a)
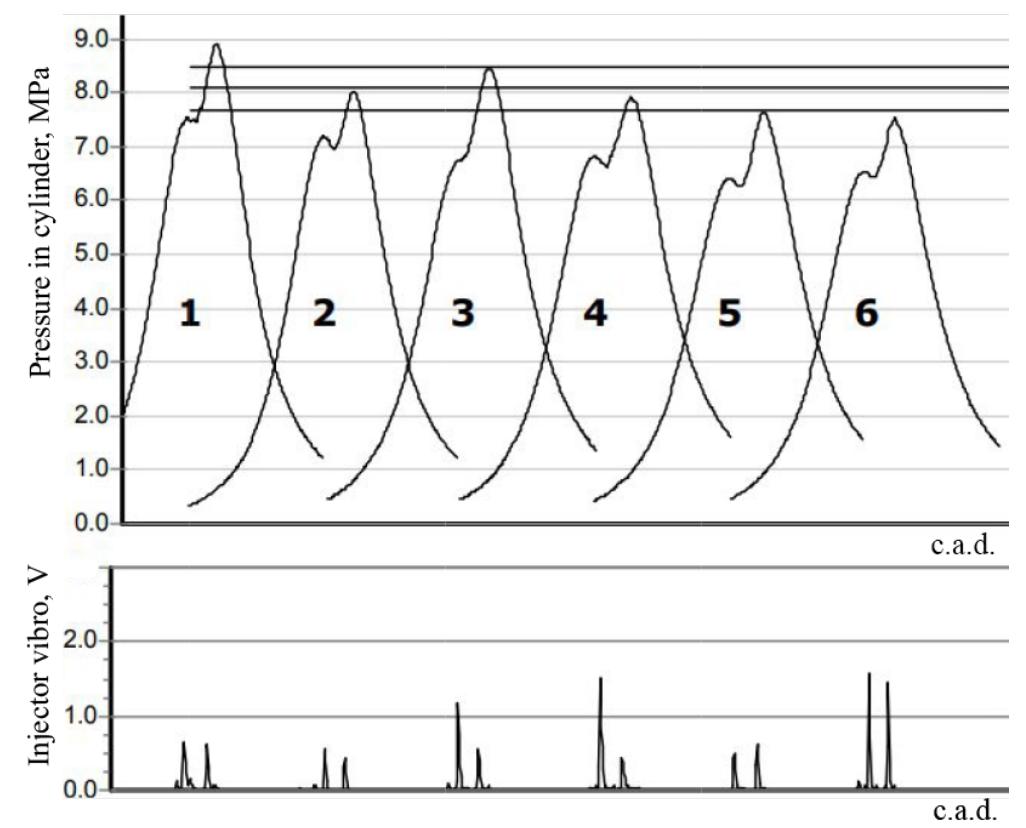

b)

FiguRE 1. DEPAS Handy report summary. "Injector vibro" - the signal of vibration sensor, which shows fuel injection valve's opening and closing timing: a) $n_{\text {crank }}=66 \mathrm{rpm}$, b) $n_{\text {crank }}=75 \mathrm{rpm}$. 

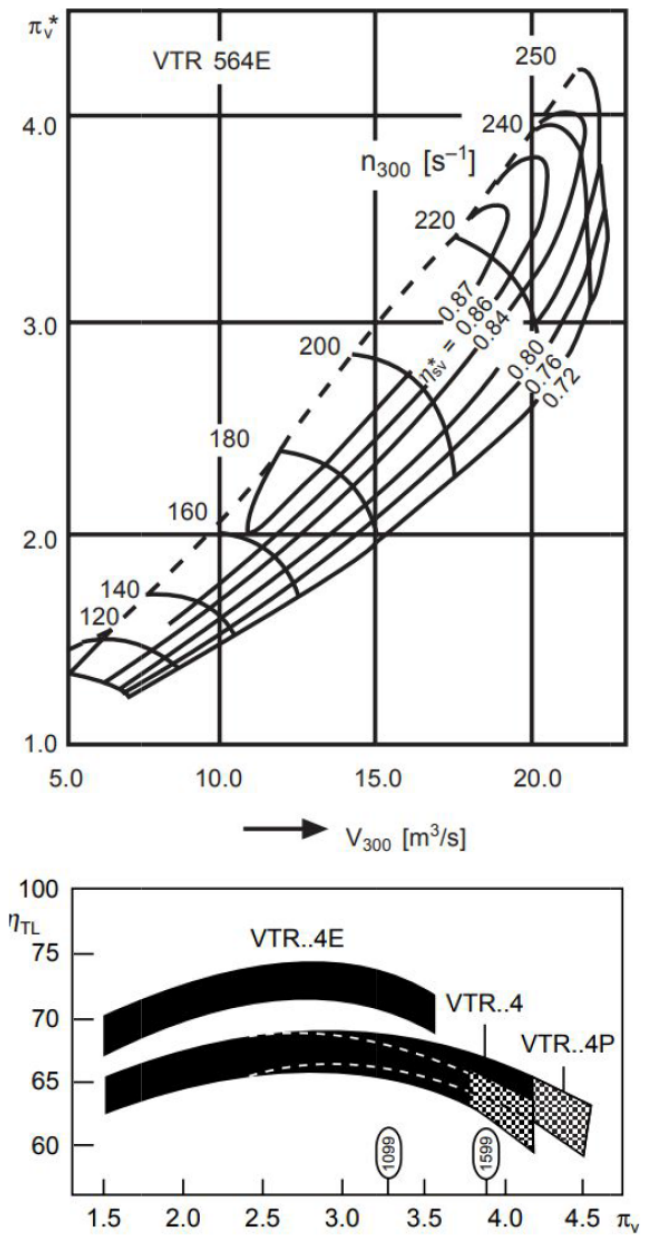

FiguRE 2. Manufacturer's performance maps ABB VTR 564 turbocharger [14.

seating. So, in terms of gas-dynamics, valve closing occurs about 25 c.a.d. in advance of the mechanical closing (which is detected by DEPAS Handy).

To consider unsteady gas flow effects, the 1-D sub-models were applied to the intake ports' channel and exhaust runner

Figure 4 demonstrates the comparison between simulated and experimental engine parameters. The standard deviation for the maximum pressure is $2 \%, 4.2 \%$ for compression pressure, $4 \%$ for scavenging pressure, $3.5 \%$ for turbocharger speed ( $8.9 \%$ if measurements error is included), $3.2 \%$ for brake specific fuel consumption and $2.5 \%$ for fuel pump index. The relatively big deviation in brake specific fuel oil consumption could be explained by the assumed fuel oil lower calorific value.

The value of turbocharger's speed at engine's $75 \mathrm{rpm}$ from sea trial is disputable and seems as some sort of measurements error. The diagrams of compression pressure and turbocharger speed in relation to the level of scavenging pressure (Figure 4 at the bottom) help to prove it. The level of the scavenge air pressure in the case of correct turbocharger adjustment is determined by the turbocharger speed. In addition, if the actual compression ratio is constant, the level of pressure at the end of the compression is determined directly by the level of scavenge air pressure, so this helps to confirm the correct turbocharger maps setup. It is clear that the level of scavenging pressure at $75 \mathrm{rpm}$ engine running during sea trials is pretty much on a curve, while the turbocharger speed is very small. The comparison to the experimental DEPAS Handy results proves this conclusion, so it is probably due to some mistake during measurements.

After the mathematical model setup, we have used it to find the answer for two questions: 1) what is the reason of the compression pressure difference between engine's cylinders; 2) what is the reason of maximum pressure variation by cylinder.

The typical reasons for compression pressure variation from cylinder to cylinder are: 1) uneven exhaust valve timing and 2) gas leakage through compression rings or/and exhaust valve seat.

DEPAS Handy, as was is mentioned, allows to define the actual exhaust valve closing timing with the aid of vibration sensor. Figure 5$]$ a shows the averaged results of measurements for six engine's cylinders for the 


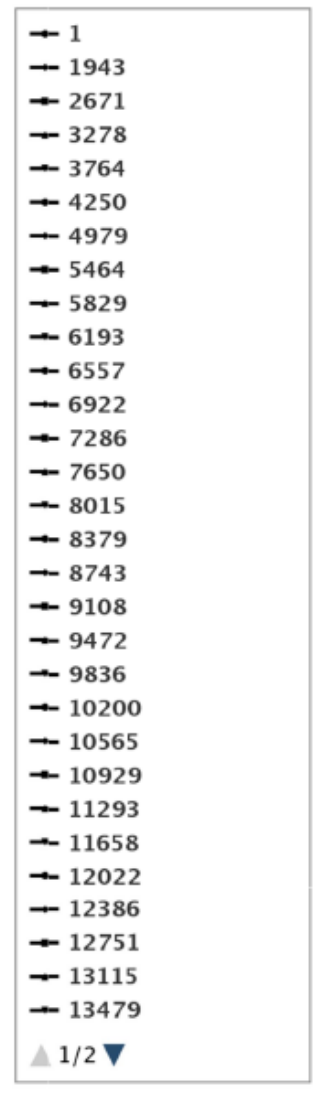

Flow map of the compressor

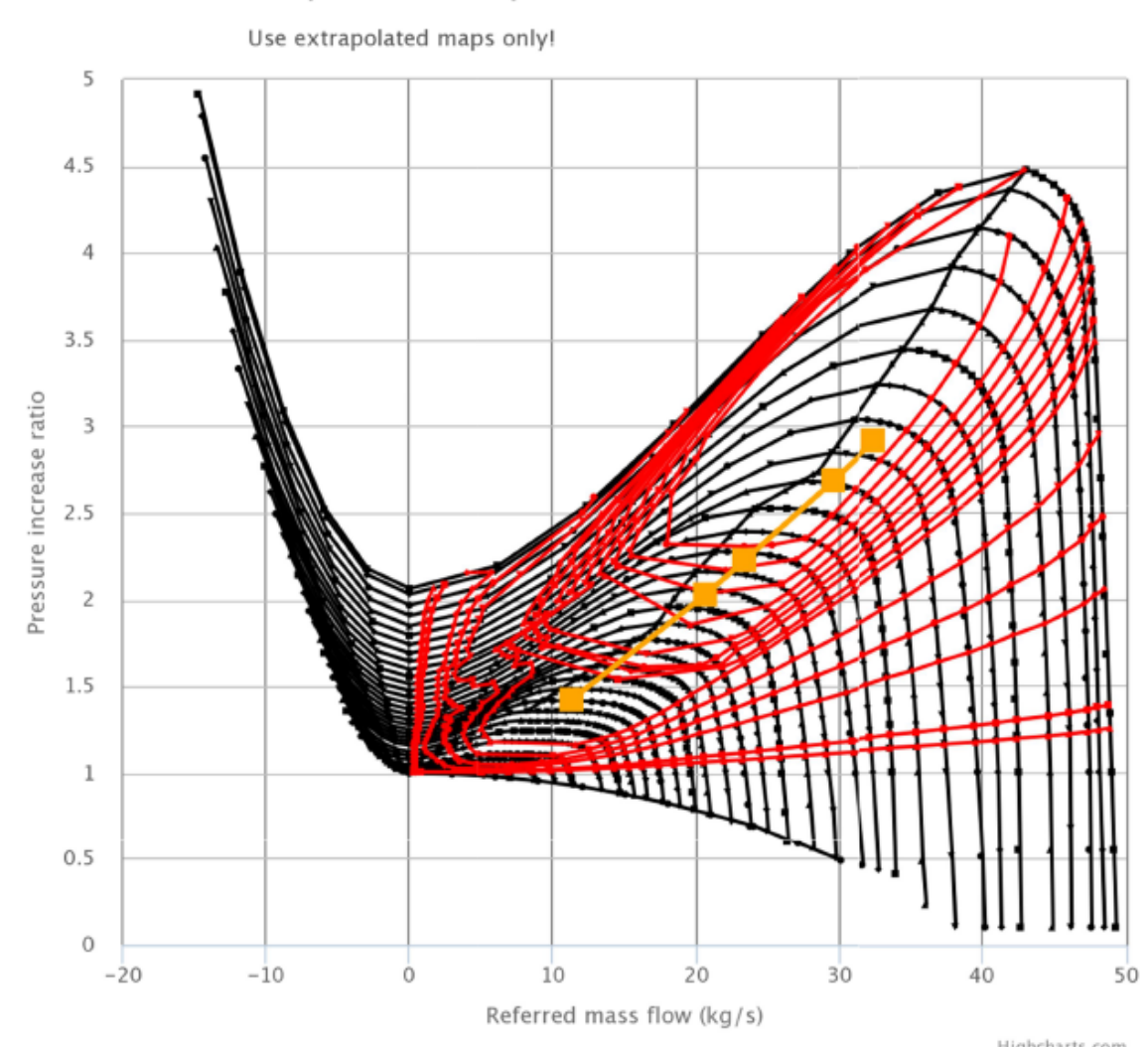

-6
-68
-159
-215
-272
-317
-362
-408
-442
-476
-510
-544
-578
-612
-680
-748
-816
- Work-point
- Transient line

Flow map of the turbine

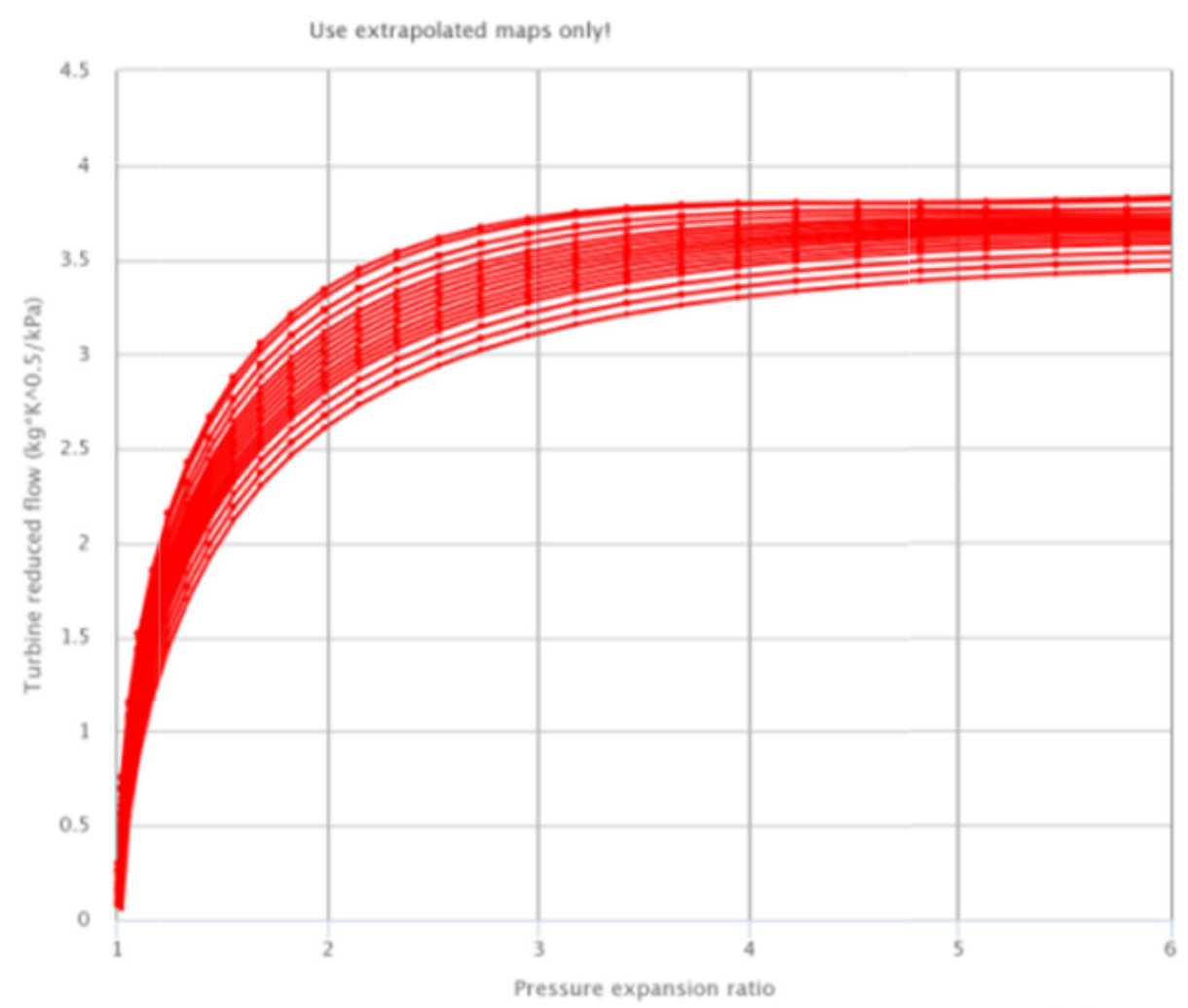

Figure 3. Extrapolated ABB VTR 564 performance maps, used in Blitz-PRO. 

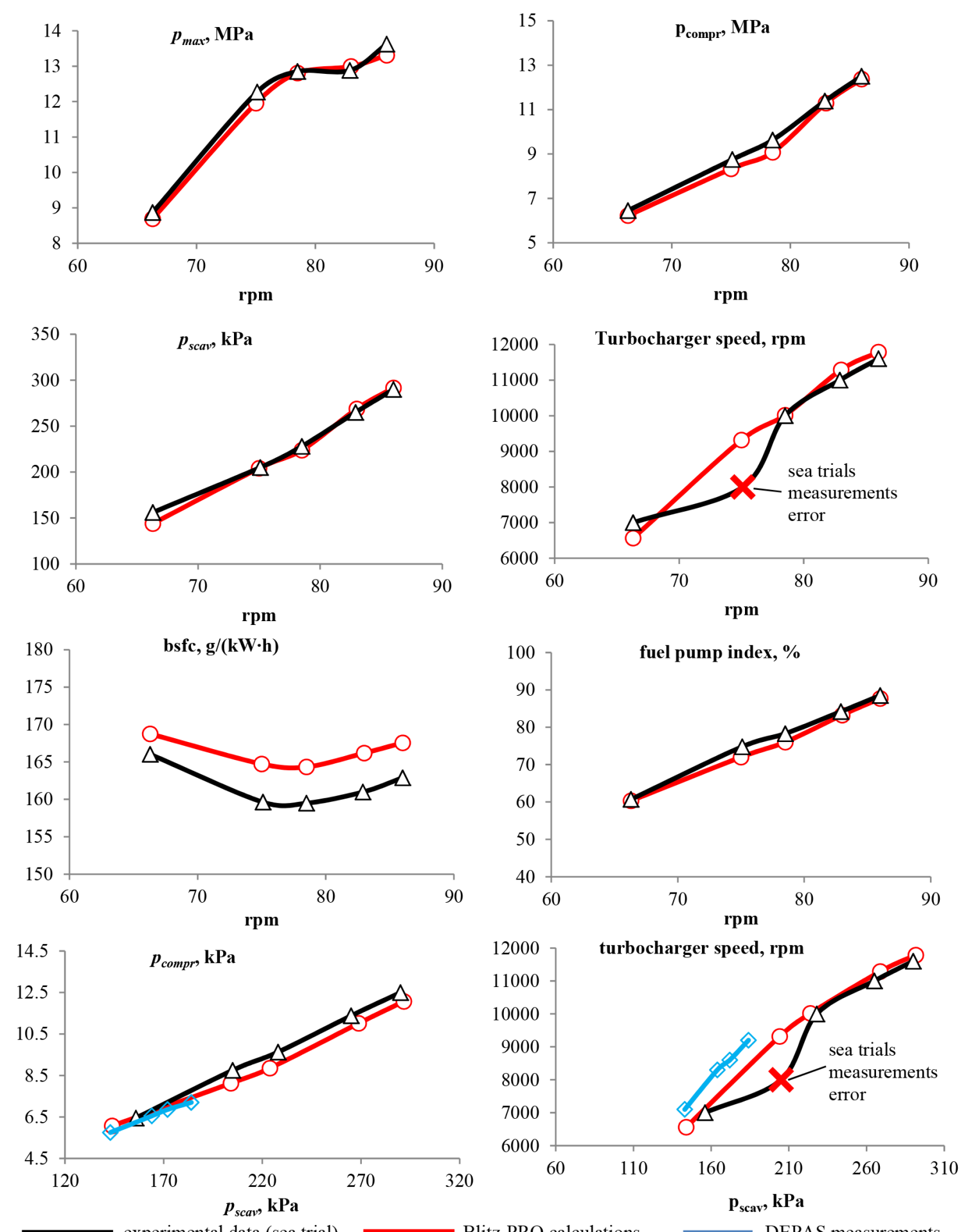

$\mathbf{X}$ - measurements error

Figure 4. MAN 6L80MCE diesel engine sea trials comparison. 

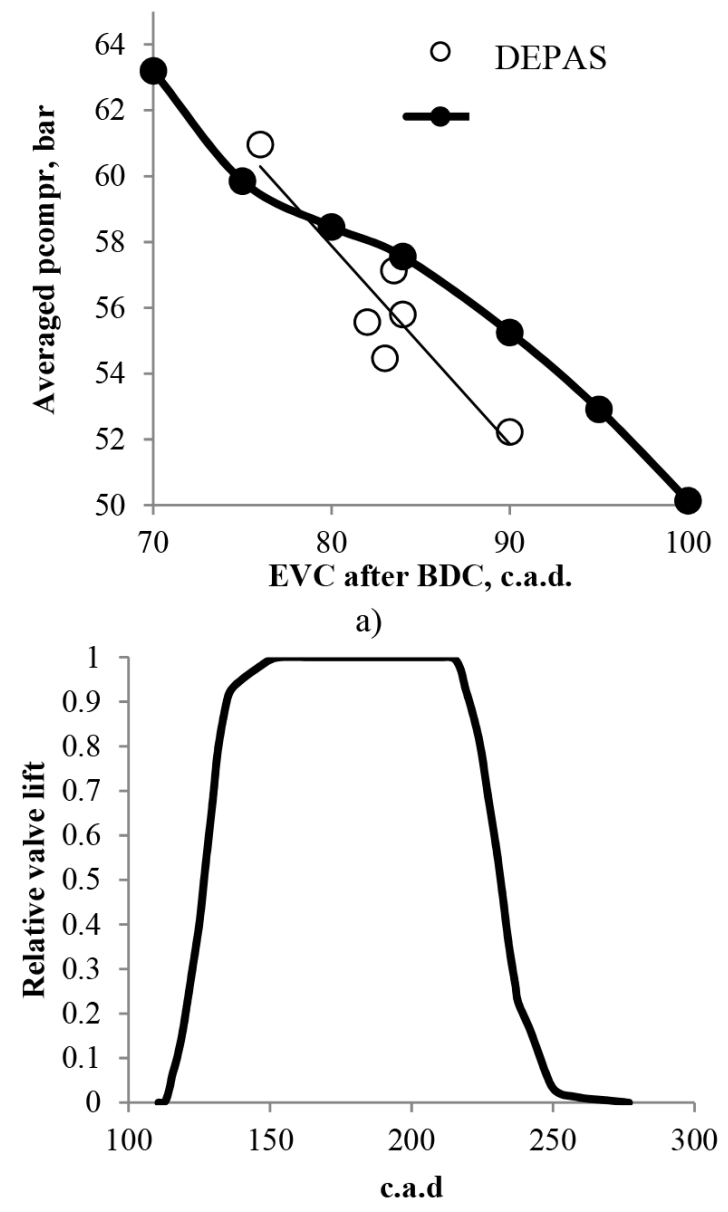

b)

FiguRE 5. Influence of exhaust valve closing timing on the compression pressure at $66 \mathrm{rpm}$ (a) and relative valve lift diagram [15], used for the simulation (b).

engine running at $66 \mathrm{rpm}$. There is a good correlation between the compression pressure and the moment of valve closing.

When comparing the experimental and simulated data, we can definitely say that the variation in $p_{\text {compr }}$ is caused by an uneven exhaust valve closing and the conditions of valves seats and compression rings are normal.

Simulation results also give a wide picture of the influence of exhaust valve closing timing on the engine operation (Figure 6). A late exhaust valve closing causes a decrease in compression temperature and, thus, longer ignition delay period. So, the combustion starts later, decreasing the efficiency and rising temperatures. Also, the late exhaust valve closing results in a volumetric efficiency decrement and smaller air excess ratio, which is also a bad influence in terms of engine parts temperatures and indicated efficiency.

The difference in the maximum pressure couldn't be explained only by the exhaust valve closing timing variation. It is also influenced by the uneven fuel injection from cylinder to cylinder. The mathematical simulation gives the estimated values of the injected fuel for every cylinder. The example for the engine running at $66 \mathrm{rpm}$ is presented in Figure 7. The simulated levels of compression pressure and maximum pressure by cylinder are close to the DEPAS Handy measurements results. The simulations show the huge irregularity in the fuel injection by about $20 \%$. This also causes the different output by the engine cylinder (about $17 \%$ ) and brake specific fuel oil consumption (about 2.7\%). Obviously, the fuel injection system requires a better adjustment to achieve the same level of the cylinder's wear, engine parts temperatures and better fuel economy. The toughest operating conditions were discovered for the number 4 engine cylinder. The combination of the late exhaust valve closing and the maximum fuel injection provides the lowest value of the air excess ratio $\alpha=2.38$, while the average is 2.6. Together with the late fuel injection, long ignition delay (because of the late exhaust valve closing) it explains the biggest exhaust valve opening in-cylinder temperature $t_{b}=1099^{\circ} \mathrm{C}$, while the average is $1030^{\circ} \mathrm{C}$. This could cause increased exhaust valve and seat wear rate for this cylinder. 

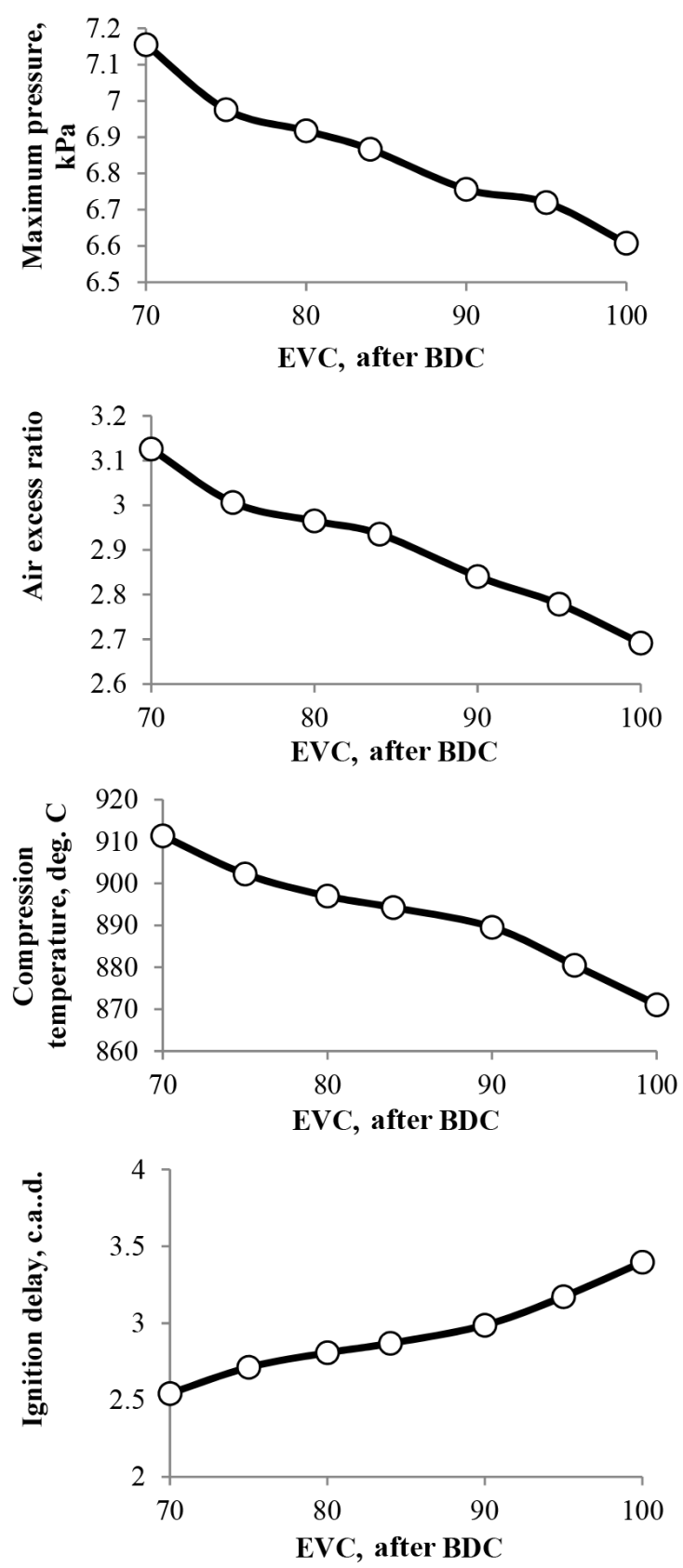

Figure 6. Calculated results of exhaust valve closing timing at $66 \mathrm{rpm}$. 

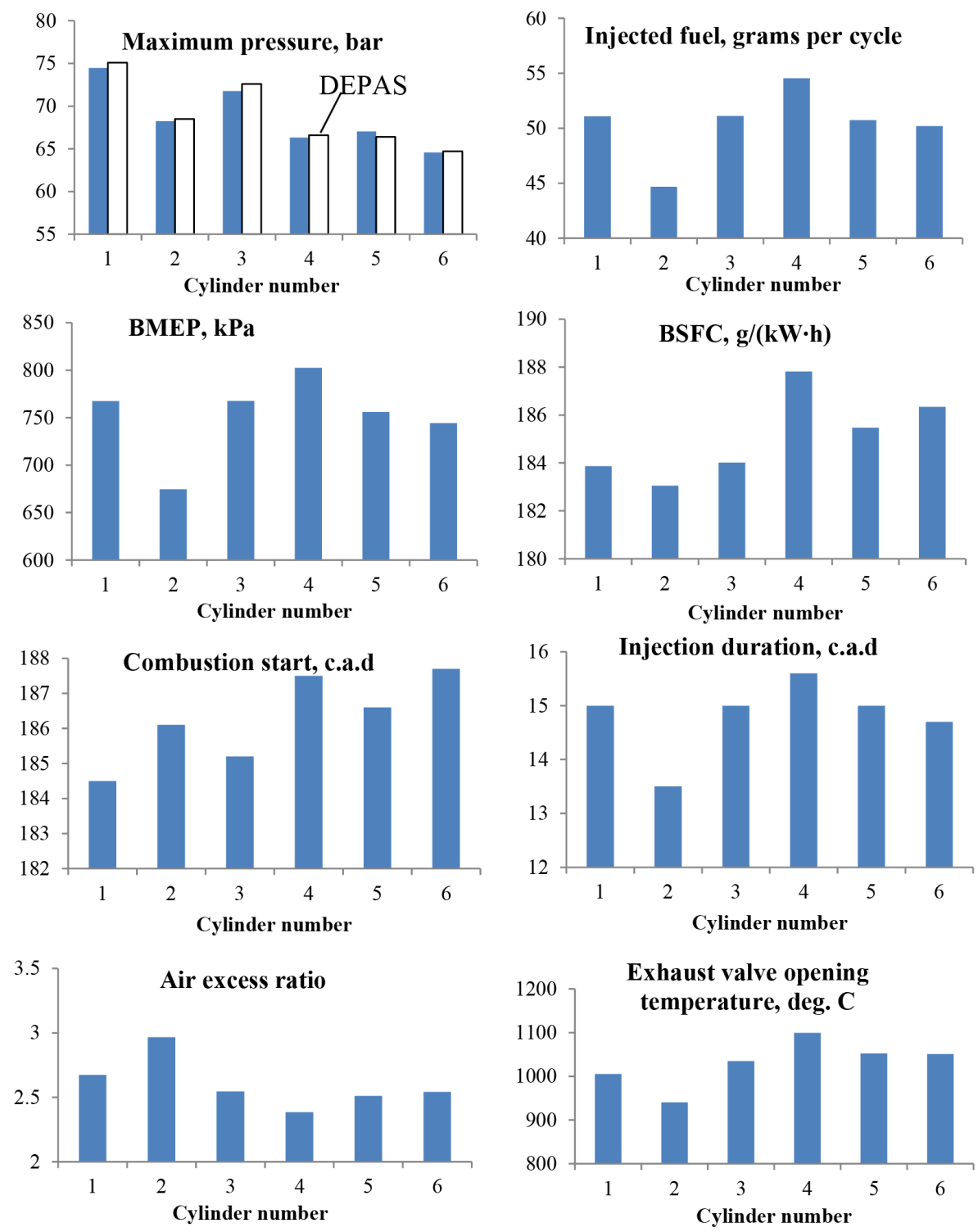

FiguRE 7 . Simulated fuel injection variation by cylinder at $n_{\text {crank }}=66 \mathrm{rpm}$.

\section{Discussion}

Mathematical simulation could be a powerful tool to analyse the experimental data from marine diesel engines diagnostic procedures. It helps to clarify the true reasons and causes of observed deviations in engine system's operation, such as fuel-injection and turbocharging systems. For two-stroke marine engine diagnostic issues, the mathematical simulation provides:

(1.) An estimation of the fuel-injection and power load irregularity by engine cylinder;

(2.) A detection of the most loaded cylinder in terms of the greatest in-cylinder temperatures at the exhaust valve opening;

(3.) An explanation of the compression pressure variation by engine's cylinders, which could be caused by the difference in the exhaust valve closing between the cylinders, or by piston rings or exhaust valve leakages;

(4.) Revealing the influence of exhaust valve closing on the engine in-cylinder parameters, such as gas exchange processes, fuel combustion, exhaust gases temperatures;

(5.) An ongoing diagnostics of the turbocharger operation.

This approach can be used not only for older engines, which are not equipped with the self-diagnostic systems, but also for modern engines as it helps to reduce the amount of necessary sensors and provides a flexibility in terms of solving issues.

The mathematical simulation also helps to make the forecast of engine operation at different loads and speeds as the experimental measurements generally have limited possibilities because of the conditions of the 
ship operation. However, the mathematical simulation needs calibration procedures based on the experimental measurements to provide accurate calculations. It also demands an interpretation of the simulation results by a highly trained specialist.

\section{Conclusions}

The combination of a mathematical simulation with direct measurements provides more possibilities in the field of marine diesel engine diagnostics. It helps to provide accurate diagnostics during a vessel operation even in challenging conditions of variable environmental parameters and lack of experimental measurements. Blitz-PRO provides an easy-to-use ICE operating processes simulation product, available online, which is accessible from a personal computer, tablet or smartphone. It could be useful for ICE diagnostic issues, combining fast calculations for all types of internal combustion engines without device storage usage. The mechanical engineer can monitor the engine during its lifetime, using mathematical simulations to define possible deviations in the operating process.

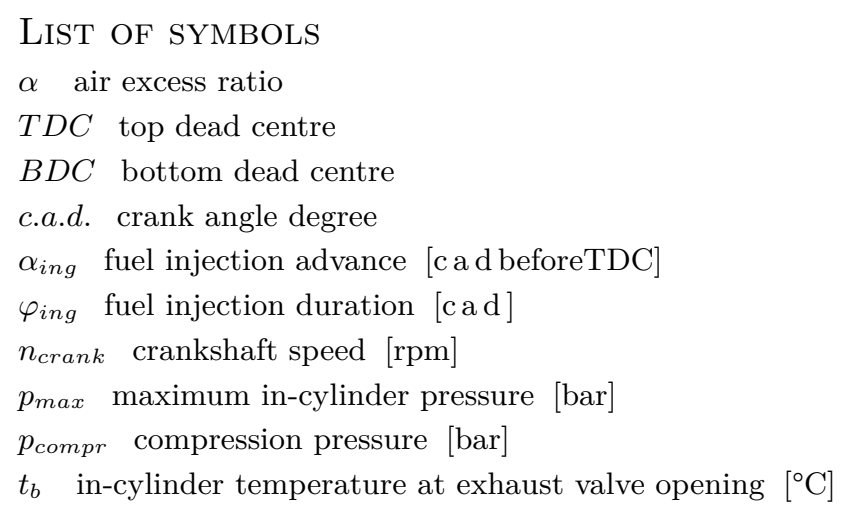

\section{REFERENCES}

[1] A. Agarwal, J. Gupta, N. Sharma, A. Singh. Model-Based Fault Detection on Modern Automotive Engines. In: Advanced Engine Diagnostics. Energy, Environment, and Sustainability. Springer, Singapore, 2019. https://doi.org/10.1007/978-981-13-3275-3_9

[2] S. Simani, C. Fantuzzi, R. Patton. Model-Based Fault Diagnosis Techniques. In: Model-based Fault Diagnosis in Dynamic Systems Using Identification Techniques. Advances in Industrial Control. Springer, London, 2003. https://doi.org/10.1007/978-1-4471-3829-7_2

[3] P. Kučera, V. Píštěk, A. Prokop, K. Řehák. Measurement of the powertrain torque. engineering mechanics proceedings 24:449-452, 2018. https://doi.org/10.21495/91-8-449

[4] R. Varbanets, O. Fomin, V. Píštěk, et al. Acoustic method for estimation of marine low-speed engine turbocharger parameters. Journal of Marine Science and Engineering 9(3), 2021. https://doi.org/10.3390/jmse9030321

[5] P. Novotny, V. Pistek, L. Drapal, et al. Efficient approach for solution of the mechanical losses of the piston ring pack. Proceedings of the Institution of Mechanical Engineers, Part D: Journal of Automobile Engineering 227(10):1377-1388, 2013. https://doi.org/10.1177/0954407013495187

[6] J. Desantes, J. Lopez, J. Garcia-Oliver, L. Hernández. Application of Neural Networks for Prediction and Optimization of Exhaust Emissions in a H.D. Diesel Engine. Springer, London, 2002. https://doi.org/10.4271/2002-01-1144.

[7] R. A. Varbanets, S. A. Karianskiy. Analyse of marine diesel engine performance. Journal of Polish CIMAC, Gdansk pp. 269-275, 2012.

[8] S. Neumann, R. Varbanets, O. Kyrylash, et al. Marine diesels working cycle monitoring on the base of imes gmbh pressure sensors data. Diagnostyka 20(2):19-26, 2019. https://doi.org/10.29354/diag/104516.

[9] R. A. Varbanets, V. I. Zalozh, A. V. Shakhov, et al. Determination of top dead centre location based on the marine diesel engine indicator diagram analysis. Diagnostyka 21(1):51-60, 2020. https://doi.org/10.29354/diag/116585

[10] D. S. Minchev. Blitz-pro. user's manual, 2018. http://blitzpro.zeddmalam.com/application/index

[11] D. S. Minchev, A. V. Nagirnyi. Application of the computational mesh with variable time step for ice operating cycle synthesis. Herald of Aeroenginebuilding (1):32-38, 2017. https://doi.org/10.15588/1727-0219-2017-1-6

[12] G. Woschni. A universally applicable equation for the instantaneous heat transfer coefficient in the internal combustion engine. SAE Technical Paper pp. 3065-3083, 1967. https://doi.org/10.4271/670931

[13] N. F. Razleitsev. Modeling and Optimization of Combustion Procedure in Diesel Engines. Kharkov University Publishers, 1980. 
[14] M. D. . Turbo. Me-b.3 engines with variable exhaust valve timing. 2013, https://marine.man-es.com/docs/ librariesprovider6/mun/me-b-3-engines-with-variable-exhaust-valve-timing.pdf?sfvrsn=c2ddeaa2_13

[15] E. by Doug Woodyard. Pounder's Marine Diesel Engines and Gas Turbines. Eighth edition. Elsevier Butterworth-Heinemann, 2004.

[16] D. S. Minchev, Y. L. Moshentsev, A. V. Nagirnyi. Extrapolation of turbocharger radial turbine characteristics. Aerospace Engineering and Technology: National Aerospace University - "Kharkiv Aviation Institute" , NAU "KhAI" (10(87)):173-133, 2011. http://nti.khai.edu:57772/csp/nauchportal/Arhiv/AKTT/2011/AKTT1011/Minchev.pdf.

[17] D. S. Minchev, Y. L. Moshentsev, A. V. Nagirnyi. Extrapolation of experimental centrifugal compressors maps. Proceedings of National University of Shipbuilding (4):89-98, 2011. https://docplayer.ru/ 28442566-Ekstrapolyaciya-eksperimentalnyh-harakteristik-centrobezhnyh-kompressorov.html. 